\title{
A EXPERIÊNCIA DO MONITORAMENTO HIDROCLIMÁTICO EM UM PROJETO DE EXTENSÃO COM A ESCOLA FAMÍLIA AGRÍCOLA E O ASSENTAMENTO DO BAIXÃO, ITAETÊ-BA.
}

\section{The experience of hydroclimatic monitoring in a project of extension with the agricultural family school and the settlement of Baixão, Itaetê-BA.}

\section{La experiencia del monitoreo hidroclimático en un proyecto de extensión con la escuela familiar agrícola y el asentamiento del Baixão, Itaetê-BA.}

Suílian Sampaio de Jesus ${ }^{1}$ https://orcid.org/0000-0002-3875-3695

Jémison Mattos dos Santos ${ }^{2}$ https://orcid.org/0000-0002-0934-4294

Ângela Carine Felix de Oliveira Matos ${ }^{3}$ https://orcid.org/0000-0002-6141-4317

\footnotetext{
${ }^{1}$ Bacharelanda em Geografia-UEFS. Bolsista do projeto de extensão Água da vida. UEFS, email: ssj.uefs@gmail.com

${ }^{2}$ Pesquisador e Coordenador do Projeto de extensão Água da vida. Laboratório de Estudos da Dinâmica e Gestão do Ambiente Tropical - GEOTRÓPICOS-UEFS, email: jemisons@uefs.br

${ }^{3}$ Licencianda em Geografia-UEFS, Bolsista voluntária do projeto de Extensão email: cfmatos.uefs@ gmail.com
}

\section{Resumo}

Trata-se de um trabalho de popularização das ciências, realizado por meio do projeto de extensão 'Água da Vida', envolvendo professores, estudantes, atores locais, etc., visando capacitar, trocar experiências-saberes e revelar a importância do uso racional dos recursos hídricos e do solo, com aporte teórico-conceitual e metodológico voltado para o monitoramento hidroclimático. No qual foram realizadas oficinas, discussões em grupo, trabalhos de campo, uso de instrumentos de precisão e a atividade pedagógica 'A Escola Vai Até o Rio, proporcionando aos participantes executarem medições de variáveis climáticas e hidrológicas, e a reflexão sobre a importância de obtenção de medidas quantitativas, para dar suporte à análise e avaliação ambiental mais consistente, para realização do diagnóstico ambiental participativo da bacia hidrográfica do Una

Palavras-chave: Monitoramento Hidroclimático. Recursos Hídricos. Popularização das ciências.

\footnotetext{
Abstract

It is a work of popularization of the sciences, carried out through the 'Water of Life' extension project, involving teachers, students, local actors, and so on. It seeks to train, exchange experiences-knowledge and reveal the importance of the rational use of water resources and soil, with a theoretical-conceptual and methodological support for hydroclimatic monitoring. In which workshops, group discussions, fieldwork, use of precision instruments and the pedagogical activity 'The School Goes to Rio, providing the participants with measurements of climatic and hydrological variables, and the reflection on the importance of obtaining of quantitative measures, to support the
} 
analysis and more consistent environmental assessment, to carry out the participative environmental diagnosis of the Una basin.

Keywords: Hydroclimatic Monitoring. Water Resources. Popularization of sciences.

\section{Resumen}

Se trata de un trabajo de popularización de las ciencias, realizado por medio del proyecto de extensión 'Agua de la Vida', involucrando a profesores, estudiantes, actores locales, etc., visando capacitar, intercambiar experiencias-saberes y revelar la importancia del uso racional de los recursos recursos hídricos y del suelo, con aporte teórico-conceptual y metodológico orientado hacia el monitoreo hidroclimático. En el que se realizaron talleres, discusiones en grupo, trabajos de campo, uso de instrumentos de precisión y la actividad pedagógica 'La Escuela va hasta Río, proporcionando a los participantes realizar mediciones de variables climáticas e hidrológicas, y la reflexión sobre la importancia de obtención de medidas cuantitativas, para dar soporte al análisis y evaluación ambiental más consistente, para la realización del diagnóstico ambiental participativo de la cuenca hidrográfica del Una.

Palabras clave: Monitoreo Hidroclimático. Recursos Hídricos. Popularización de las ciencias.

\section{Introdução}

Este artigo advém das experiências vividas no projeto de extensão denominado “Água da Vida: o rio que vai traz a vida também”, com a comunidade envolvida que se encontra na zona rural de Itaetê, na localidade conhecida como Colônia, na Chapada Diamantina (nesta fase do projeto, são assistidas cerca de 50 famílias, entre jovens, crianças e professores).

A escolha deste tema está em valorizar o conhecimento acadêmico, principalmente quando se tem o propósito de popularizar as ciências, promover a integração da UEFS com a Secretaria de Ensino do Município de Itaetê, através do envolvimento direto da EFACI e do Assentamento Baixão, visando primordialmente levantar dados, interpretar, analisar, capacitar e difundir o conhecimento científico sobre hidroclimatologia, recursos hídricos, dinâmica fluvial (p.ex: das águas e sedimentar), renaturalização e revitalização de rios, conservação ambiental e uso sustentável dos recursos hídricos, por meio da participação comunitária. 
É importante ressaltar, que a manutenção da EFA se dá principalmente através da contribuição financeira e voluntária das famílias dos discentes.

Um dos objetivos principais é difundir o conhecimento sobre os recursos hídricos e a conservação ambiental através do uso racional, por meio de práticas sustentáveis de baixo custo, que estão alinhadas com o planejamento das atividades sócio produtivas e o ambiente em seu conjunto. Além disso, visa capacitar e instrumentalizar os atores sociais envolvidos para demonstrar a importância do conhecimento científico através do uso de um conjunto de instrumentos de precisão (p.ex.: estação meteorológica digital portátil) e do estudo das características hidroclimáticas, dentre elas, está em saber quais as melhores condições para o plantio, uma vez que com essa informação pode-se evitar maiores prejuízos para agricultura.

Entende-se que a participação comunitária da EFA é significativa, pois o estabelecimento de parcerias e o aporte vindo de projetos extensionistas possibilita alavancar futuros planos para EFA, orientados para promover a melhoria da qualidade dos sistemas ambientais e de vida, o fortalecimento do conhecimento tradicional e refletir sobre possíveis alternativas para, por exemplo, gerar outras fontes de renda para a comunidade.

Este projeto também possibilitou aos bolsistas desenvolver uma maior conscientização sobre o uso racional dos recursos hídricos e o planejamento ambiental, que por consequência contribui positivamente com a formação acadêmica/profissional, vislumbrando a promoção de futuras relações mais harmônicas entre a sociedade e natureza.

\section{Materiais e métodos}

Para o desenvolvimento desse estudo, fez-se um levantamento bibliográfico e cartográfico para selecionar os materiais mais satisfatórios, a fim de elaborar a base teórico-conceitual e instrumental que serviu de apoio para as discussões ao longo da pesquisa. Para isso, fundamentou a investigação com base em alguns autores clássicos, a exemplo de: Maia (1997), Rebouças (2006), Ribeiro (2008) e outras produções acadêmicas, tais como: artigos em periódicos especializados e documentos técnicos disponíveis na internet ou em sites institucionais, a exemplo da UEFS, UFPE e USP, visando robustecer o conhecimento sobre a temática em foco e contribuir para o processo do aprendizado dos participantes no referido projeto. 
Durante 02 meses, foi pensada metodologicamente e planejada cada etapa de uma oficina que foi realizada com a comunidade na ocasião do trabalho de campo. Etapa esta que se constituiu uma das mais fundamentais do projeto, que ocorreu entre 03 e 05 de dezembro em 2017, e merece destaque algumas atividades práticas realizadas: 'o dia de campo', que no primeiro momento foram feitas medições no canal do rio Una e no rio Invernado, a exemplo da seção transversal, da vazão, da largura, do comprimento e da profundidade, por meio de dois métodos diretos (uso de molinete) e indiretos (meios manuais, medições sem instrumentos de precisão).

Além das práticas de observação da dinâmica fluvial efetuadas às margens do rio Una, também foram feitas coletas de sedimentos em suspensão, em pontos previamente selecionados. Quanto às medições de variáveis climáticas (manhã, meio-dia e fim de tarde, nos mesmos horários) tais como: pressão, temperatura e velocidade do vento (termo anemômetro digital Incoterm, modelo TAN 100 e o barômetro digital), com o auxílio da equipe do projeto de extensão, professores e discentes da EFA.

Constatou-se com essas atividades práticas que os participantes demostraram mais interessados, estimulados, a partir do relato de um dos discentes - "o ensino com o uso de aparelhos torna-se bem mais atrativo e quando desenvolvido de acordo com a realidade vivida é mais legal”.

Para execução do conjunto de procedimentos realizados foram utilizados equipamentos tais como: micromolinete, garrafa coletora de sedimentos em suspensão, GPS de navegação, bússolas Silva, de Bruton.

Por fim, efetuou-se a interpretação e análise do conjunto maior de dados levantados, que possibilitou tecer algumas considerações sobre o monitoramento hidroclimático, o uso de instrumentos de precisão e a necessidade de preservação ou conservação dos recursos hídricos na EFACI no entorno.

\section{Resultados e discussões}

A água é um bem natural e insubstituível para o conjunto da sociedade e diante de tamanha importância, é necessário enfatizar que a sua distribuição no planeta Terra é diferenciada e encontra-se em diversas formas (estado líquido, gasoso, sólido). De acordo com Maia (1997) apesar das águas ocuparem 71\% da superfície terrestre, muitos desconhecem a possibilidade de uma crise de água potável no futuro. Do total de água disponível 97\% estão nos oceanos (água salgada), 2,07\% está em forma de geleiras (forma sólida) e apenas $0,63 \%$ está na forma de água potável (forma líquida). 
O acesso à água potável para o consumo humano vai além de uma necessidade é um direito assegurado por lei. Além de ser a protagonista essencial da vida, é advinda de sua utilização à produção de mercadorias tanto na área industrial quanto na agricultura.

Esta, por sua vez, é um recurso fundamental para os seres vivos e requer um cuidado extremo, bem como o desenvolvimento de pesquisas que assegurem melhores formas de manejo, por meio do planejamento integrado dos recursos hídricos, tornando possível definir medidas que promovam mudanças de hábitos (culturais arraigadas) capazes de promover o uso sustentável e evitar desperdícios das águas.

Assim, as situações danosas ocasionadas pelo uso inadequado da água não seria a tônica das sociedades contemporâneas capitalistas (que atualmente conduz parte do Planeta) insidiosamente para um período duradouro de escassez hídrica, que já atinge muitas nações causando deseconomias e perdas de vidas humanas. Diante disso, frisa-se o importante valor dado à água como referenciado por Rebouças (2006):

A água é um elemento essencial à vida no planeta Terra, em especial ao homem, no que tange ao abastecimento para consumo humano, ao desenvolvimento das atividades industriais e agrícolas e ainda à vida dos animais e vegetais. Contudo, é um recurso vulnerável às modificações no ambiente de origem, por onde percolam ou onde são armazenadas, devido aos diferentes usos e ocupações dados pelas ações humanas (REBOUÇAS, 2006, p.01).

Quando o uso desse recurso natural é efetivado de modo irracional, desencadeiam-se inúmeros prejuízos no âmbito social e econômico. Em geral, no mundo contemporâneo as necessidades humanas cada vez mais suprimem e põem em riscos os recursos naturais que intensifica o atual quadro de pressões ambientais negativas, comprometendo a disponibilidade e o acesso à água de boa qualidade.

Somos altamente dependentes da água, e ao mesmo tempo, os responsáveis pela sua preservação e conservação em prol de condições ótimas, que permita uma vida saudável e reduza os conflitos por água, pois a violenta e crescente disputa por água, que tem se tornado algo comum, principalmente quando a escassez indica rumos quase que irreversíveis tão bem exemplificados por Ribeiro (2008):

Água é fonte de conflito porque sua distribuição natural não corresponde à sua distribuição política. Em alguns países os recursos hídricos são mais que suficientes para abastecer as necessidades de seu povo. Mas eles são raros em outros. Como o estilo de vida hegemônico está baseado no consumo incessante de mercadorias, o uso da água para a produção industrial tende a aumentar, o que pode desencadear novos conflitos pelo seu acesso. (RIBEIRO, 2008 p.17) 
Diante do quadro atual, é de responsabilidade da sociedade, mas principalmente dos setores que mais consomem água (indústria e agronegócio), exercitar o uso racional da água e fortalecer as ações que estimulem a adoção dos princípios norteadores de sua apropriação sustentável, como definida na lei 9.433 de 8 de janeiro de 1977 (Política Nacional de Recursos Hídricos).

Por isso, para que esse conhecimento teórico trabalhado nas oficinas e trabalhos práticos fosse mais bem compreendido pela comunidade, discutiu-se com mais ênfase a temática dos recursos hídricos e o manejo adequado da água, ressaltando que parte expressiva da renda da comunidade é oriunda de atividades ligadas diretamente à água (p.ex: os ribeirinhos da agricultura familiar e os inúmeros plantios irrigados observados na bacia hidrográfica do Rio Una).

Durante a etapa de campo, realizou-se a primeira oficina prática sobre importância da conservação dos recursos hídricos e do solo (foto 1). Nesse momento de ensino-aprendizagem, os estudantes e professores da EFA contribuíram com seus saberes e suas experiências tradicionais de imensurável valor. Assim, foi possível integrar o saber popular com o conhecimento acadêmico em prol da reflexão sobre: melhores práticas agrícolas; manejo adequado do solo; segurança alimentar e hídrica para serem implantadas no curto, médio e longo prazo na EFA.

Foto 1- Oficina Prática sobre a Importância e Conservação dos Recursos Hídricos e do Solo, na EFA - 2017

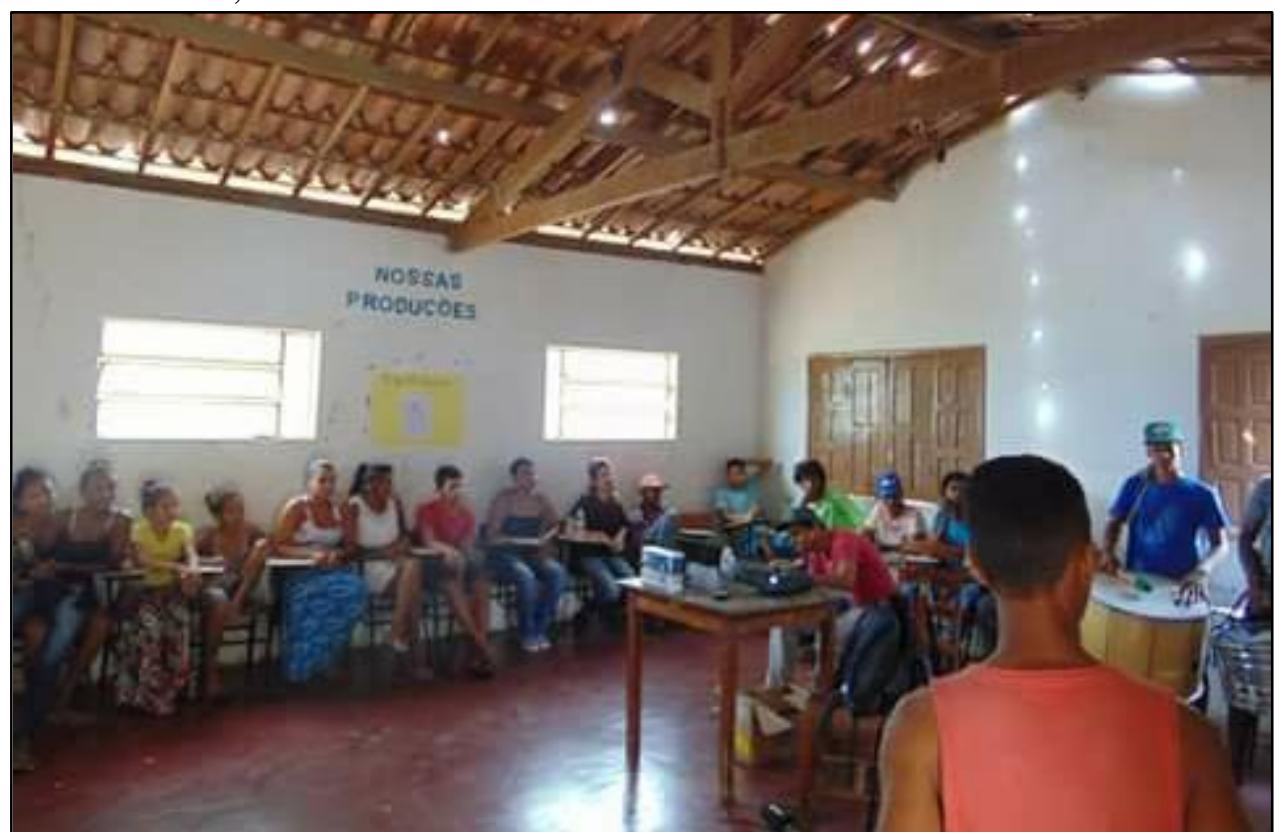

Fonte: Fotografia de Suílian Sampaio; trabalho de campo (2017) 
Ao reconhecer a importância do conhecimento popular faz-se necessário preservar suas práticas, principalmente, aquelas que contribuem para assegurar o equilíbrio entre as condições ambientais e as atividades socioprodutivas. Por isso, neste contexto é muito importante a Pedagogia da Alternância, pois esta busca valorizar o que se faz no ambiente familiar associando aos conhecimentos da educação do campo, embasada por Caliari et al (2002) como:

Na Pedagogia da Alternância, o saber prático obtido junto à família, na execução das tarefas e a teoria, obtida na escola durante a troca de experiências e absorção dos conteúdos ensinados, se fundem. Assim, podem auxiliar a aprofundar a compreensão do que ocorre no dia-adia, na família e escola, e onde o conhecimento emerge, se amplia e se consolida, facilitando ao jovem alternar e valorizar aquilo que ele faz e sabe. É na vinculação do conhecimento escolar com a ambiência familiar que o jovem reflete sobre seu meio e elabora seus marcos de referência. (CALIARI et al, 2002 p.18)

É um momento significativo de troca de conhecimentos entre o ambiente escolar e familiar, que contribui positivamente com a realidade do estudante do campo (este compartilha com os familiares os conhecimentos adquiridos na escola). Por isso, é crucial para o semiárido Baiano o desenvolvimento de projetos de extensão como o Água da Vida: o rio que vai traz à vida também.

Outra importante atividade didático-prática realizada fora da sala de aula foi a intitulada 'Escola Vai Até o Rio', que visa aprofundar ainda mais os conhecimentos do espaço de vivência dos estudantes e professores da EFA. No qual as principais atividades executadas estão ligadas às medições de variáveis hidroclimáticas; tais como: temperatura, direção e velocidade do vento, sendo estas efetuadas com o apoio de instrumentos de precisão.

Antes, foram apresentados os conteúdos do Kit da estação meteorológica digital (igual ao modelo que foi instalada na comunidade no início do projeto em 2012, Nexus Modelo 35.1075). Bem como os equipamentos e sensores remotos que coletam e transmitem dados meteorológicos como: a temperatura interna e externa, umidade, quantidade e a intensidade da chuva.

Na sequência foram realizadas medições no canal do rio Una e no rio Invernado, com o apoio de vários instrumentos entre eles o: clinômetro, termo-anemômetro, GPS e a bússola Silva e de Bruton. Os estudantes envolvidos se mostraram atentos e 
comprometidos com a produção de conhecimento de forma mais interativa e prática (ilustração 2)

Foto 2 - Atividade prática de medição da seção transversal por método não convencional- o dia em que a "Escola Vai Até o Rio", rio Una - 2017.

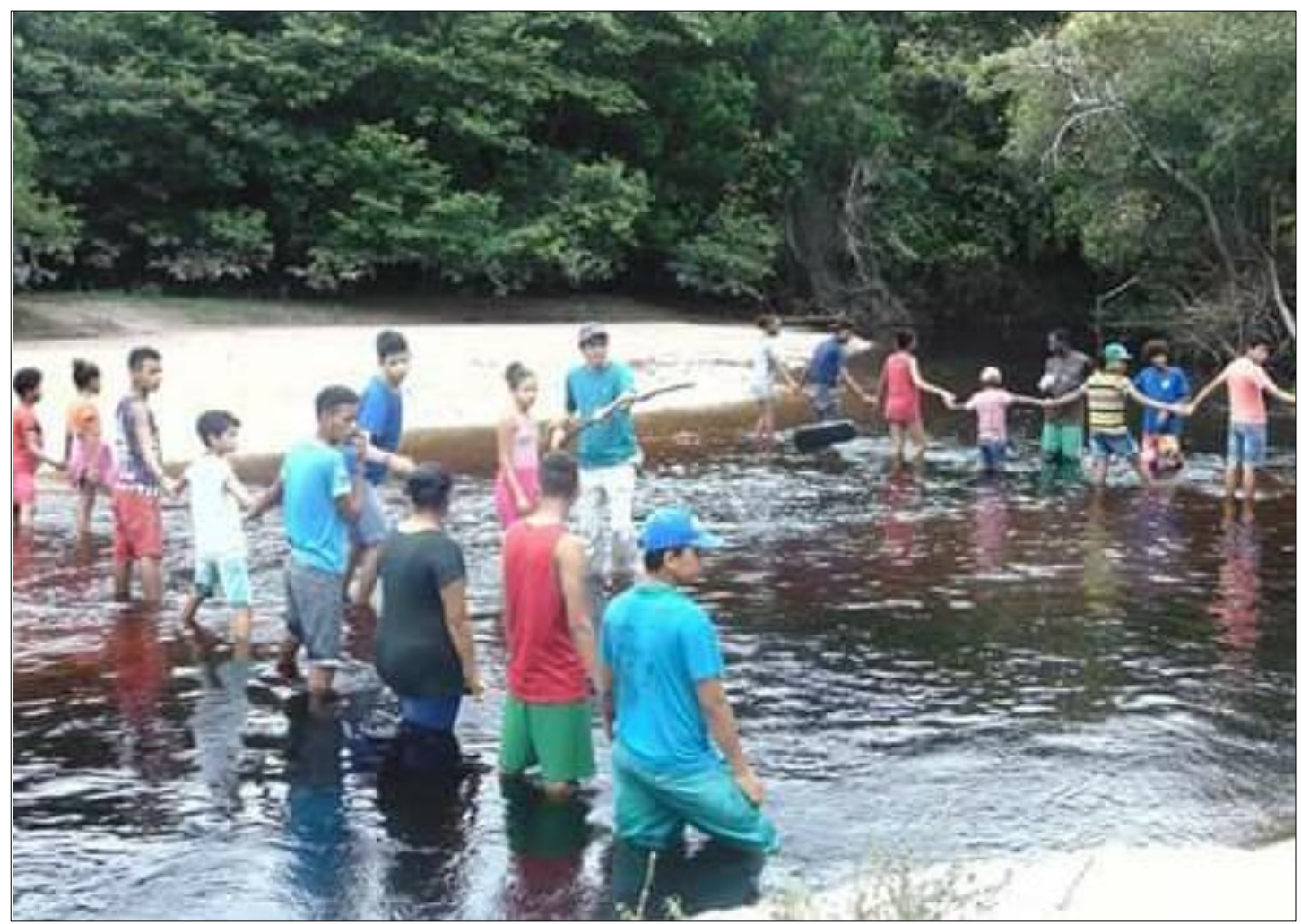

Fonte: Fotografia de Ângela Carine; trabalho de campo (2017)

A atividade em foco visa demonstrar aos membros da EFA, como são realizados alguns procedimentos para tomar medidas no canal fluvial, a exemplo da vazão em um trecho do rio Una, usando o método indireto (do flutuador que é muito utilizado dado sua simplicidade e a carência de equipamentos sofisticados que possuem valores financeiros elevados) e outro método direto (Correntômetro de Hélice ou MicroMolinete Hidrométrico - marca HidroMec).

A medição indireta é uma forma manual utilizada com os estudantes para medir a largura, a profundidade do canal por meio de uma vara de $1,5 \mathrm{~m}$ e uma garrafa pet lançada ao rio para registrar o tempo e a distância percorrida (a área da seção transversal foi definida pela média da seção molhada a montante e a jusante), adotou-se um trecho retilíneo de $6 \mathrm{~m}$ de comprimento para obter a velocidade do fluxo (recomendado para estudos que não exigem tanta precisão). Uma série de seis repetições foi definida e os valores máximos e mínimos obtidos foram excluídos para a estimativa da velocidade média. A vazão total do referido método é calculada pelo produto da velocidade média 
corrigida pela área de seção transversal média. O coeficiente de correção para vazão aplicado foi na ordem de 0,80 para o rio Una, pois este possui um fundo arenoso (valor levantado no trabalho da Environmental Protection Agency - EPA, 1997).

Já para a medição direta foi utilizado o Micro-Molinete Hidrométrico para registrar a velocidade de corrente de água (entre 0,025 até $5,0 \mathrm{~m} / \mathrm{s}$ ) onde os dados posteriormente foram sistematizados para efetuar o cálculo da vazão (a medição e a integração da velocidade média na seção são bastante usadas na hidrometria de rios naturais).

\section{Considerações finais}

Por meio desta pesquisa, se ressalta a importância do fazer extensionista, fundada na experiência do projeto Água da Vida: o rio que vai traz à vida também! Que possibilitou o entendimento mais aprofundado do Semiárido Baiano-SAB e a construção de uma parceria solidária entre a Universidade e a comunidade EFA. Ampliando o leque de interpretações sobre o ambiente e produzindo outros sentidos sobre a consciência ecológica, ambiental e a urgência de estabelecer uma relação de cuidado com os recursos hídricos, com a natureza, que vai além da conservação destes, bem como despertar uma maior atenção no desempenho nas atividades socioprodutivas diárias da comunidade, buscando um arcabouço sustentável.

Através do conjunto de atividades realizadas com os estudantes nos rios próximos da EFA (rio Una e rio Invernado), onde foram utilizadas técnicas, por exemplo, para medir a temperatura, a chuva, a vazão dos rios, que geraram reflexões sobre as práticas e a possibilidade dos agentes locais aprenderem a avaliar alguns aspectos ambientais de sua comunidade (a água e o clima) com métodos mais simples. Ações estas que viabilizam produzir conhecimentos técnico-científicos com a finalidade de contribuir para o planejamento, na gestão para conservação ambiental dessa comunidade.

Uma questão central emergiu no debate - como auxiliar o desenvolvimento de práticas agrícolas sustentáveis em um ambiente semiárido que apresenta carências educacionais, financeiras e tecnológicas, associando às condições ideais do tempo para o plantio, para evitar possíveis prejuízos?

Por fim, trabalhar numa perspectiva extensionista vem se revelando a cada etapa mais um enorme desafio, principalmente, por conta das inúmeras restrições de logística 
e financeira que enfrentam às universidades baianas (a exemplo da UEFS), que seguramente interfere negativamente no desenvolvimento deste tipo particular de estudo. Uma dentre tantas outras questões importantes, que seguramente deve se tornar o centro de atenções das nossas lutas diárias, em prol de uma Universidade Pública e de excelência.

\section{Referências}

BRASIL. LEI Nº 9.433, DE 8 DE JANEIRO DE 1997, de 13 de março de 1990.

CALIARI, R. O.; ALENCAR, E.; AMÂNCIO, R. Pedagogia da alternância e desenvolvimento local. Revista Organizações Rurais \& Agroindustriais, Lavras, v. 4 n.2, dezembro, 2002.

CARVALHO, T. M. de. Técnicas de medição de vazão por meios convencionais e não convencionais. Revista Brasileira de Geografia Física, Recife, v. 1, n.1, p.75-85, Maio/Agosto, 2008.

EPA. ENVIRONMENTAL PROTECTION AGENCY. Stream Flow. In: Office Of Water: Monitoring Water Quality. Volunteer stream monitoring: a methods manual. Washignton: EPA, 1997. Cap 5, p. 134-138.

MAIA N. R. F. Água para o desenvolvimento sustentável. Revista água em revista, Belo Horizonte, v.5, n. 9, p. 21-32, Novembro, 1997.

REBOUÇAS, A. da C.; BRAGA, B.; TUNDISI, J. G. ACADEMIA BRASILEIRA DE CIÊNCIAS (Org.). Águas doces no Brasil: capital ecológico, uso e conservação. 3. ed. rev. e map. São Paulo: Escrituras, 2006. 713p

RIBEIRO, W. C. Geografia política da água. São Paulo: Annablume, 2008. 162p. 
A experiência do monitoramento hidroclimático em um projeto de extensão com a escola família agrícola e o assentamento do Baixão, Itaetê-BA.

JESUS, S. S.; SANTOS, J. M. dos; MATOS, A. C. F. de O.

\section{Agradecimentos}

Agradecemos o apoio da equipe de profissionais do Laboratório de Estudos e Dinâmica da Gestão do Ambiente Tropical (GEOTRÓPICOS-UEFS), pelo suporte de sua infraestrutura e por compartilhar os instrumentos de precisão (GPS, fluviômetro, clinômetros, bússolas, termo anemômetro, etc.).

Agradecemos a toda comunidade da EFACI em nome de dona Vera pelo acolhimento, pelo carinho, respeito conosco e trabalho em parceria, como também a PROEX-UEFS pelo apoio e colaboração durante o desenvolvimento das atividades de trabalho de campo. 